${ }^{4}$ Flamant F, Rodary C. Rhabdomyosarcoma trial SIOP III. Proceedings of the XIIIth meeting of the international society of pediatric oncology. Marseille, September 15-19, 1981;328-329. Amsterdam: Excerpta Medica, 1982.

${ }^{5}$ Teft M, Fernandez C, Donaldson M, Newton W, Moon ThE. Incidence of meningeal involvement by rhabdomyosarcoma of the head and neck in children. Cancer 1978;42:253-8.
- Maurer HM. The intergroup rhabdomyosarcoma study II: objectives and study design. J Pediatr Surg 1980;15:371-2.

Correspondence to Dr S S N de Graaf, Department of Paediatrics, University Hospital, Postbox 30.001, 9700 RB Groningen, The Netherlands.

Received 15 January 1985

\title{
Isolated myocarditis in the first year
}

\author{
D J DESA \\ Department of Pathology, Children's Hospital, Health Sciences Centre, Winnipeg, Canada
}

SUMMARY Over a period of nearly 40 years, 20 cases of isolated myocarditis were traced from 3086 necropsies. Seventeen occurred in infants less than 12 months of age, often with no antecedent clinical signs (sudden deaths) or with a short clinical history of less than 24 hours' duration.

A series of three infants dying from isolated myocarditis in a three month period prompted a review of the necropsy records of this hospital, tracing and comparing cases of 'isolated' and 'incidental' myocarditis.

\section{Materials and methods}

This hospital is the major referral centre in the province of Manitoba for children of all ages, and its pathology department performs most paediatric necropsies in the province.

The necropsy records and histological slides from 1945 onwards were searched for cases of myocarditis, and the histological slides were reviewed. Details of the sex, age, and heart weight of the accepted cases were abstracted and analysed. The clinical charts provided information on clinical details and results of any laboratory investigations. Where appropriate $\chi^{2}$ calculations using two by two tables were used to analyse the results.

\section{Results}

Thirty five confirmed cases of myocarditis were traced from the records of 3086 necropsies between January 1945 and June 1984. No difference in the sex ratios was discernible and the ages of the affected infants varied from 1 month to 14 years. Of the 35 affected cases, 21 were 12 months or less in age.
In 20 cases the heart was the primary organ affected and the only changes in other organs were due to cardiac failure ('isolated' myocarditis). In the remainder, myocarditis was part of a generalised infection and these cases were classified as examples of 'incidental' myocarditis (Table 1). Seventeen of the 20 cases of isolated myocarditis occurred in infants 12 months of age or less, whereas only three cases of isolated myocarditis occurred in older children. This difference in the incidence of isolated myocarditis between infants ( 12 months or less) and older children is highly significant $(\mathrm{P}<0 \cdot 001)$.

Due in part to a lack of suspicion of the underlying disease, appropriate cultures were submitted in only six of the 20 cases, who were later found to have isolated myocarditis on histologic examination. From one of these infants a Coxsackie B viral strain was isolated and an imported case of acute myocarditis due to $T$ cruzei (Chagassic myocarditis) was identified histologically and ultrastructurally.

Duration of disease. In 14 of the 20 cases with isolated myocarditis, a clinical history of less than 24 hours was obtained. Eleven of the 14 infants presented as sudden deaths without any prodromal symptoms or signs. Thirteen of the 14 patients were under 12 months (Table 2).

Table 1 Isolated myocarditis and age distribution

\begin{tabular}{|c|c|c|c|c|c|}
\hline \multirow[t]{2}{*}{ Age } & \multicolumn{5}{|c|}{ Cases of myocarditis } \\
\hline & \multicolumn{2}{|c|}{ 'Isolated' } & \multicolumn{2}{|c|}{ 'Incidental' } & Total \\
\hline$<1$ month & 1 & & 1 & & \\
\hline 2-6 months & 8 & $17^{*}$ & 2 & 4 & 21 \\
\hline $7-12$ months & 8 & & 1 & & \\
\hline \multirow[t]{2}{*}{$>12$ months -14 years } & 3 & $*$ & 11 & & 14 \\
\hline & 20 & & 15 & & 35 \\
\hline
\end{tabular}

The difference in incidence between infants and older children is highly significant $(\mathrm{P}<0 \cdot(001)$. 
Table 2 Isolated myocarditis; length of clinical presentation and age

\begin{tabular}{|c|c|c|c|}
\hline \multirow[t]{2}{*}{ Age } & \multicolumn{2}{|c|}{ Length of clinical presentation } & \multirow[t]{2}{*}{ Total } \\
\hline & $<24$ hours & $>24$ hours & \\
\hline$<1$ month & 1 & - & \\
\hline 2-6 months & $13^{*}$ & 2 & 17 \\
\hline $7-12$ months & 6 & 23 & \\
\hline \multirow{2}{*}{$>12$ months -14 years } & $*$ & 2 & 3 \\
\hline & 14 & 6 & 20 \\
\hline
\end{tabular}

The difference between infants under 12 months of age and older children is significant $(P<0 \cdot 02>0 \cdot 01)$.

Pathological findings. Compared with the published normal values for age, using the data of Coppoletta and Wolbach ${ }^{1}$ and the linear regression graphs based on that data of Shankle et al, ${ }^{2} 16$ of the 20 patients in the study had heart weights in excess of the $95 \%$ confidence limits, and a further two infants had heart weights in excess of the $99 \%$ confidence limits.

In all patients with isolated myocarditis, the heart seemed dilated with a variable degree of endocardial opacification and mottling of the myocardium.

Histological findings. Histologically, a diffuse interstitial mononuclear inflammatory infiltrate with a noticeable predominance of lymphocytes was found. An associated interstitial oedema and scattered foci of necrotic muscle fibres was seen in both ventricles and atria. Mural thrombi were not seen. The endocardium showed variable degrees of fibroelastotic scarring in 11 of the 20 infants. In four infants obvious foci of hypertrophied fibres could be found scattered through both ventricles.

A detailed examination of the atrioventricular conduction system in four cases, did not find any lesions.

\section{Discussion}

Myocarditis is rare in adults ${ }^{3}$ and it was a surprise to find 20 cases of isolated myocarditis in this series.
Whitehead ${ }^{5}$ found 18 cases of isolated myocarditis in 12815 necropsies on patients of all ages; by comparison with that study, isolated myocarditis was found over four times more frequently in this series. It particularly affected infants under 12 months of age, who could present as a sudden death without prodromal symptoms or signs. The reasons for the higher incidence in infants less than 12 months of age is not clear. Immunological deficits are unlikely to be responsible since these would be expected to predispose to generalised infections rather than isolated involvement of a single organ.

The increased heart weight, despite the short clinical history, in 14 cases suggests that a latent phase of myocarditis may exist. Presumably cardiac compensation is possible during this period and deterioration occurs when an arrhythmia develops.

The lack of suspicion of the presence of isolated myocarditis leads to a failure to submit appropriate samples for culture. The need to submit samples of the myocardium for virologic studies in all cases of sudden death, needs to be stressed.

Many of the earlier cases in this series were studied and coded by Dr J Hoogstraten, to whom a special indebtedness is acknowledged. Miss M Kosheluk and Mrs D Patching traced the cases and charts and typed the manuscript.

\section{References \\ ${ }^{1}$ Coppoletta JM, Wolbach SB. Body length and organ weights of infants and children: study of body lengths and normal weights of more important vital organs of body between birth and 12 years of age. Am J Pathol 1933;9:55. \\ 2 Shankle WR, Landing BH, Gregg J. Normal organ weights of infants and children: graphs of values by age, with confidence intervals. Pediatr Pathol 1983;1:399. \\ 3 Woodruff J. Viral myocarditis: a review. Am J Pathol 1980; 101:427. \\ 4 Hudson RB. Cardiovascular pathology. London: Edward Arnold, 1970;782. \\ 5 Whitehead R. Isolated myocarditis. Br Heart J 1965;27:230.}

Correspondence to Professor D J deSa, Children's Hospital, Health Sciences Centre, 678 William Avenue, Winnipeg, Manitoba, Canada R3E 0W1.

Received 13 December 1984 